\title{
Preliminary field survey on Mycobacterium bovis infection in cattle herds using caudal fold intradermal tuberculin test in two Northeastern States of Nigeria
}

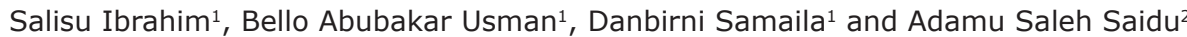

1. Department of Veterinary Medicine, Ahmadu Bello University, Zaria, Nigeria; 2. Department of Veterinary Public Health and Epidemiology, College of Veterinary Science, Lala Lajpat Rai, University of Veterinary and Animal Sciences, Hisar, Haryana, India.

Corresponding author: Salisu Ibrahim, e-mail: sihadejia@gmail.com

Co-authors: BAU; ubagombe@gmail.com, DS: drdanbirni2007@yahoo.com, ASS: adamudvm13@gmail.com Received: 28-06-2018, Accepted: 17-09-2018, Published online: 01-11-2018

doi: 10.14202/vetworld.2018.52-58 How to cite this article: Ibrahim S, Usman BA, Samaila D, Saidu AS (2018) Preliminary field survey on Mycobacterium bovis infection in cattle herds using caudal fold intradermal tuberculin test in two Northeastern States of Nigeria, Int J One Health 2018;4:52-58.

\begin{abstract}
Aim: A survey was conducted to determine the prevalence of bovine tuberculosis (bTB) in two states of Northeastern Nigeria, namely Bauchi and Gombe States, between February 2010 and November 2014 using caudal fold tuberculin (CFT) skin test.

Materials and Methods: A total of 5489 cattle were screened using single CFT in Bauchi and Gombe States. Of the 5489 cattle, 2116 cattle were from 189 herds in five testing areas in Bauchi State and 3373 cattle in 217 herds from five testing areas from Gombe State.

Results: On the basis of the CFT, herd prevalence obtained was 56.08\% in Bauchi and 55.29\% in Gombe State, while the individual animal prevalence was $10.96 \%$ in Bauchi and $13.73 \%$ obtained in Gombe State. The prevalence based on the testing areas in Bauchi State, Alamari had the highest prevalence with $19.4 \%$ and Disina the lowest with $9.0 \%$, while in Gombe State, Wakaltu had the highest prevalence with $20.9 \%$ and Poshereng the lowest with $8.0 \%$. Cows were more likely to have tuberculosis lesions than bulls $(\mathrm{p}=0.0035)$ in Bauchi State, but there was no significant difference in Gombe State $(p=0.166)$. However, a statistically significant association $(p<0.05)$ was observed among the cattle age groups with cattle $\geq 4$ years having higher odds for tuberculin reactivity compared to those below the age of 4 years in Bauchi State only.
\end{abstract}

Conclusion: There is the need to strengthen routine meat inspection and public health awareness programs on the zoonotic nature of bTB among the abattoir workers and the herdsmen.

Keywords: bovine tuberculosis, cattle herds, caudal folds, Northeastern Nigeria, tuberculin test.

\section{Introduction}

Bovine tuberculosis (bTB) is a disease caused by a specific type of bacterium called Mycobacterium bovis. bTB usually affects animals such as cattle, but it can also affect all mammals causing sickness, coughing, and eventual death. It can be transmitted from animals to humans as well as to other animals [1]. The disease has been reported in 176 countries of the world as one of the important bovine diseases leading to great economic losses [2]. In cattle, exposure to the organism can result in a chronic disease that jeopardizes animal welfare and productivity and in some countries leads to significant economic losses by causing ill health and mortality [3].

Moreover, human TB of animal origin caused by $M$. bovis is becoming increasingly evident in developing countries [4,5]. In Sub-Saharan Africa, humans and animals share the same microenvironment,

Copyright: Ibrahim, et al. Open Access. This article is distributed under the terms of the Creative Commons Attribution 4.0 International License (http://creativecommons.org/licenses/ by/4.0/), which permits unrestricted use, distribution, and reproduction in any medium, provided you give appropriate credit to the original author(s) and the source, provide a link to the Creative Commons license, and indicate if changes were made. The Creative Commons Public Domain Dedication waiver (http:// creativecommons.org/publicdomain/zero/1.0/) applies to the data made available in this article, unless otherwise stated. watering points, feeding facilities, and grazing land. In such countries where bTB is still common, and pasteurization of milk is not practiced, an estimated $10-15 \%$ of pulmonary tuberculosis is caused by $M$. bovis [6,7]. Cattle with tuberculosis lose $10-25 \%$ of their productive efficiency; direct losses due to the infection become evident by the decrease in 10-18\% milk and 15\% reduction in meat production [8]. Apart from effects on animal production, it has also significant public health importance [9].

In the developing countries, unfortunately, bTB has received little attention by way of surveillance, control, and/or eradication program. It has been reported by Thoen and Bloom [10] that nearly $85 \%$ of cattle and $82 \%$ of the human population in the developing countries live in areas where the disease is prevalent and/or only partially controlled. There is a close association between the human and cattle populations. Nevertheless, the available information is limited due to inadequate disease surveillance and lack of better diagnostic facilities $[11,12]$. Information on genotypic characteristics of $M$. bovis, a strain affecting the cattle population in Nigeria, is limited [13]. It is important to obtain such information to monitor the transmission pattern and spread of the disease among cattle [7]. In developing countries like Nigeria, the socioeconomic 
situation and low standard of living areas for both animals and humans are contributing more in TB transmission between human to human and human to cattle or vice versa $[14,15]$.

In Nigeria, the disease had been reported in many parts of the country [16-20]. Despite the lack of effective identification, control, and prevention strategies, bTB is endemic in Nigeria. This study was designed to determine the $M$. bovis infection in cattle herds using caudal fold tuberculin (CFT) test in two Northeastern States of Nigeria.

\section{Materials and Methods}

\section{Ethical approval}

The purpose of this study was explained to the cattle owners and informed consent was obtained.

\section{Study area}

The survey was conducted in Bauchi and Gombe States of Nigeria. Bauchi State lies between latitudes $10^{\circ} 10^{\prime}$ and $10^{\circ} 33 \mathrm{~N}$ and longitudes $9^{\circ} 40^{\prime}$ and $10^{\circ} 13^{\prime}$ (Figure-1a). The climate of the states is semi-arid, characterized by a long dry season. The climatic variables vary considerably during the year and are erratic. The temperature regime is warm to hot. The mean annual temperature is about $25^{\circ} \mathrm{C}$ in the coolest month and $39^{\circ} \mathrm{C}$ during the hottest month. Evapotranspiration is very high and relative humidity is highest in August (up to $80 \%$ ) and low in January-March (23-30\%) when it is moderated by the harmattan. The year is characterized by marked dry and wet seasons. The wet season is roughly 4 months (June-September), while the dry season is 7-8 months (October-May). The total annual rainfall ranges from " $600 \mathrm{~mm}$ " in the north to " $1000 \mathrm{~mm}$ " in the southern part of the state. Most of the state falls within the Sudan Savanna vegetation belt, but traces of Guinea Savanna vegetation are found in the parts of the southern districts (Figure-1b). Bauchi State occupies a total land area of $49,119 \mathrm{Km}^{2}$ representing about $5.3 \%$ of Nigeria's total land mass [21]. Gombe State is located between latitude $9^{\circ} 30^{\prime}$ and $12^{\circ} 30^{\prime} \mathrm{N}$ and longitudes $8^{\circ} 45^{\prime}$ and $11^{\circ} 45^{\prime} \mathrm{E}$ of the Greenwich Meridian [22]. The state is in the Northeastern part of Nigeria, with its capital at Gombe town. It is on an altitude of $540 \mathrm{~m}$ above the sea level and covers an estimated land mass of $20,265 \mathrm{~km}^{2}$ and has a population of $1,820,415$ inhabitants [22]. The state has two distinct climates, the dry season (December-March) and the rainy season (April-November) with an average rainfall of "850 mm," with the mean maximum monthly temperature of $37^{\circ} \mathrm{C}$ and relative humidity of $94 \%$ in August and 10\% in December.

\section{Study design}

This study was a cross-sectional screening test using a caudal fold test in some selected cattle herds in both Bauchi and Gombe States. The field study was composed of primary screening test using SIT in some selected cattle herds in both Bauchi and Gombe States.

\section{Herds selection}

A herd in this study is defined as a group of cattle kept together by a pastoralist or on a farm with at least 20 animals, and only herds with a population of at least 20 cattle were selected. All the cattle were tested in each selected herd. Indigenous cattle from the pastoralist herds and a few herds kept by individuals and government-owned institutions were sampled. The multistage sampling procedure as described by Martins et al. [23] was used. In the first stage, each of the states, three senatorial districts were used, and

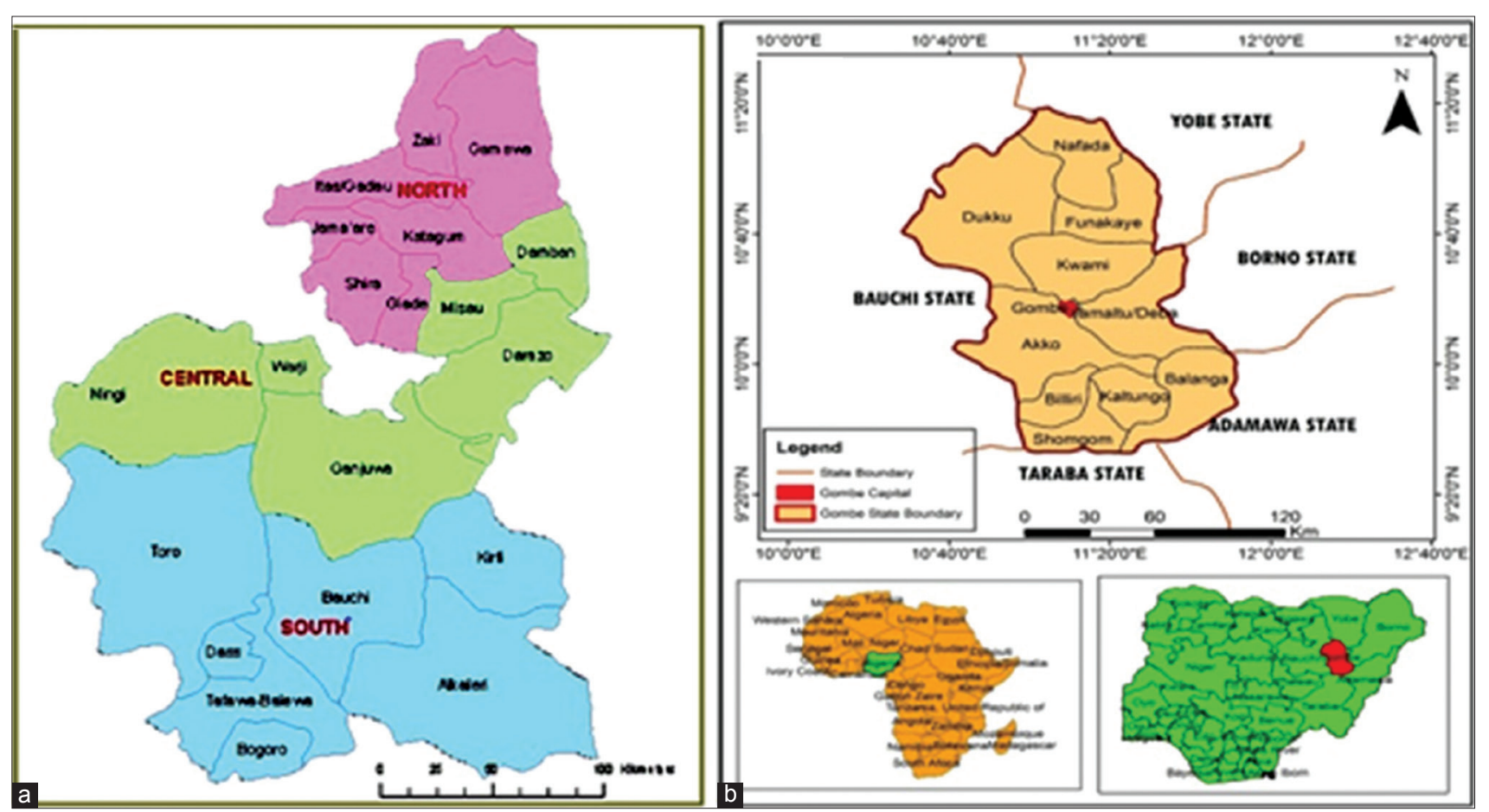

Figure-1: (a) A map showing the study area in Bauchi State, northeastern, Nigeria and (b) a map showing the study area in Gombe State, northeastern, Nigeria. 
then three areas with the highest concentration of livestock in each district were selected using simple random sampling as the second stage. In the third stage, 5 herds were selected based on their system of management (Nomadic, Settled, Organized farms and Government farms if any).

\section{Cattle selection}

All the 5489 heads of cattle tested were serially numbered using oil-based synthetic enamel paint applied at the back of the animal. The numbering was large and heavy enough so that they were easily read at least 7 days after application. The animals were clinically examined, and information pertaining to the individual animal was collected. These data included an identification number, location (village), and breed, sex, dry, pregnant or lactating (for females), and body condition score (BCS) (poor, fair, and good).

\section{Tuberculin testing of cattle}

Each animal was subjected to a single caudal fold test (SCF). The animal was restrained in the field as described by "Alhaji [16]." A site about one-third of the distance from the base of the tail on the right and ventral side of the tail was chosen and cleaned with dry cotton wool. One-tenth $0.1 \mathrm{~mL}$ of purified protein derivative of " $M$. bovis" (5000 "i.u/ml") was then carefully deposited intradermally using semi-automatic tuberculin syringe [24]. $72 \mathrm{~h}$ post-injection, the site was examined by visualization and palpation to identify reaction based the followings: Any increase in caudal fold thickness, size, or sensitivity either observed or palpated at the injection site was considered response or positive test. The size of responses may vary. Responses may be small, hard, pear-shaped, diffuse, circumscribed, or large responses, and all responses recorded.

\section{Statistical analysis}

Data were analyzed using Statistical Package for the Social Sciences (IBM, USA) Version 20.0. Odds ratio (OR) and 95\% CI were used to measure the likelihood and strengths of association between variables and bTB (M. bovis). Tables were constructed using the Microsoft Excel 2010. Values of $p<0.005$ were considered statistically significant throughout the study.

\section{Results}

A total of 5509 cattle were screened using CFT test in Bauchi and Gombe States. Of the 5509 cattle, 2116 cattle were from 189 herds in five testing areas in Bauchi State and 3393 cattle in 217 herds from five testing areas from Gombe State. Regarding the prevalence based on the testing areas in Bauchi State, Alamari had the highest prevalence with $19.4 \%$ and Disina was the lowest with $9.0 \%$, while in Gombe State testing areas, Wakaltu had the highest prevalence with $20.9 \%$ and Poshereng had the lowest with $8.0 \%$ (Table-1). The herd prevalence of bTB in Bauchi State based on this tuberculin test was $56.08 \%(106 / 189)$ while the herd prevalence in Gombe State was $55.29 \%$. With regard to individual animal prevalence, Bauchi State recorded an overall animal prevalence of $10.96 \%$ while Gombe State had $13.73 \%$ animal prevalence (Table-2). From the study, cows had significantly $(p<0.005)$ higher risk of coming down with TB than bulls in Bauchi State while no significant difference was shown in Gombe State (Table-3). Furthermore, it was observed that chances of cattle being infected with bTB increased with age, positivity of cattle 7 years or older have the highest (18.9\%) while the least positivity of $10.6 \%$ in Bauchi. It was also observed that there was significant $(\mathrm{p}<0.005)$ relationship among the age groups in Bauchi State and the management systems in Gombe State, respectively. The study has also demonstrated that White fulani breeds of cattle had higher chances $(22.13 \%)$ of coming down with the disease than Bokoloji (15.22\%) or Crossbreeds (14.67\%), but it was non significant ( $p>0.005)$. With regard to BCS, animals in Bauchi State with poor BCS had the highest lesions (18.0\%) followed by those with medium body score $(10.4 \%)$ and good BCS with $12.2 \%$. In Gombe State, animals with poor BCS had the highest chances of having lesions (16.7\%) while medium and good BCS had $11.5 \%$ and $10.5 \%$, respectively.

As for herd size, it was observed that, in Bauchi State, herds with more than 11 herds had $60.3 \%$ positivity while those with herd size $<10$ herds had $47.6 \%$ positivity. In Gombe State, the trend was observed with herd $>11$ herds having $57.1 \%$ positivity and those with $<10$ herds having $53.1 \%$. As for management, chances for observing lesions of bTB were highest in

Table-1: Distribution of suspected bovine tuberculosis in five testing areas in Bauchi and Gombe States.

\begin{tabular}{|c|c|c|c|c|c|c|c|}
\hline \multirow[t]{2}{*}{ State Bauchi } & \multirow[t]{2}{*}{ CFT Resp } & \multicolumn{5}{|c|}{ Testing areas } & \multirow[t]{2}{*}{ Overall } \\
\hline & & Tashar leda & Itas & Udugbo & Disina & Alamari & \\
\hline & Positive & $45(14.1)$ & $60(11.2)$ & $71(9.8)$ & $42(9.0)$ & $14(19.4)$ & $232(11.0)$ \\
\hline & Negative & 275 (85.9) & $476(88.8)$ & $650(90.2)$ & $425(91.0)$ & $58(80.6)$ & $1884(89.0)$ \\
\hline Total & & $320(15.1)$ & $536(25.3)$ & $721(34.1)$ & $467(22.1)$ & $72(3.4)$ & $2116(100.0)$ \\
\hline \multirow[t]{3}{*}{ Gombe } & & Poshereng & Walama & Bodor & Wakaltu & Hinna & Overall \\
\hline & Positive & $33(8.0)$ & 107 (19.6) & $115(20.1)$ & $72(20.9)$ & $136(9.1)$ & $463(13.7)$ \\
\hline & Negative & $379(92.0)$ & $438(80.4)$ & 458 (79.9) & $273(79.1)$ & $1362(90.9)$ & $2910(86.3)$ \\
\hline Total & & $412(12.2)$ & $545(16.2)$ & $573(17.0)$ & $345(10.2)$ & $1498(44.4)$ & $3373(100.0)$ \\
\hline
\end{tabular}

Figures in parenthesis represent percentage response 
Available at www.onehealthjournal.org/Vol.4/9.pdf

Table-2: Individual animal and herd level prevalence of bovine tuberculosis in Bauchi and Gombe States.

\begin{tabular}{lcccc}
\hline State & Total screened & Number positive & Prevalence 95\% CI & Negative (\%) \\
\hline Bauchi & & & & \\
$\quad$ Individual animal prevalence & 2116 & 232 & 10.96 & $1884(89.04)$ \\
$\quad$ Herd prevalence & 189 & 106 & 56.08 & $83(43.91)$ \\
Gombe & 3373 & 463 & 13.73 & $2910(86.3)$ \\
$\quad$ Individual animal prevalence & 217 & 120 & 55.29 & $97(44.7)$ \\
Herd prevalence & & &
\end{tabular}

Table-3: Association between risk factors and tuberculin reactivity of cattle in Bauchi and Gombe States.

\begin{tabular}{|c|c|c|c|c|c|c|}
\hline \multirow[t]{2}{*}{ Risk factors } & \multicolumn{3}{|c|}{ Bauchi } & \multicolumn{3}{|c|}{ Gombe } \\
\hline & Number tested & Number positive (\%) & p value & Number tested & Number positive (\%) & p-value \\
\hline \multicolumn{7}{|l|}{ Sex } \\
\hline Bulls & 573 & $50(8.7)$ & 0.0035 & 1136 & $142(12.5)$ & 0.166 \\
\hline Cows & 1543 & $182(11.8)$ & & 2237 & $286(12.8)$ & \\
\hline \multicolumn{7}{|l|}{ Age (years) } \\
\hline$<2$ & 350 & $37(10.6)$ & 0.035 & 515 & $73(14.2)$ & 0.679 \\
\hline $2-4$ & 670 & $86(12.8)$ & & 945 & $98(10.3)$ & \\
\hline $5-7$ & 520 & $75(14.4)$ & & 1234 & $210(17.1)$ & \\
\hline$\geq 7$ & 180 & $34(18.9)$ & & 679 & $82(10.6)$ & \\
\hline \multicolumn{7}{|l|}{ Breed } \\
\hline White & 1116 & $247(22.13)$ & 0.069 & 2786 & $391(14.0)$ & 0.073 \\
\hline Fulani & & & & & & \\
\hline Bokologi & 716 & $109(15.22)$ & & & & \\
\hline Cross & 293 & $43(14.67)$ & & 587 & $72(12.3)$ & \\
\hline \multicolumn{7}{|l|}{ BCS } \\
\hline Good & 253 & $32(12.2)$ & 0.063 & 773 & $81(10.5)$ & 0.857 \\
\hline Medium & 635 & $66(10.4)$ & & 986 & $113(11.5)$ & \\
\hline $\begin{array}{l}\text { Poor } \\
\text { Herd size }\end{array}$ & 1223 & $220(18.0)$ & & 1614 & 269 (16.7) & \\
\hline $1-10$ & 63 & $30(47.6)$ & 0.067 & 98 & $52(53.1)$ & 0.075 \\
\hline$\geq 11$ & 126 & $76(60.3)$ & & 119 & $68(57.1)$ & \\
\hline \multicolumn{7}{|l|}{ Management } \\
\hline Good & 201 & $12(6.0)$ & 0.083 & 815 & $103(12.6)$ & 0.003 \\
\hline Medium & 265 & $14(5.28)$ & & 920 & $120(13.0)$ & \\
\hline Poor & 1650 & $206(12.48)$ & & 1638 & $240(14.7)$ & \\
\hline
\end{tabular}

animals under poor management (14.7\%) followed by those with medium and least in animals kept under good management in Gombe States only (Table-3).

Risk factors such as herd size, BCS, and breed were also not significantly ( $>0.05)$ associated with tuberculin positivity in cattle.

\section{Discussion}

The present study has shown the individual animal prevalence of bTB to be $10.96 \%$ and $13.73 \%$ in Bauchi and Gombe States, respectively, while the herd prevalences were $56.08 \%$ and $55.29 \%$, respectively. The individual animal prevalence reported in this study is in agreement with previous reports from Nigeria by Abubakar [25], Shehu [26], and Jiwa et al. [27]. It was, however, observed that the prevalence for the two states was $12.3 \%$, which is from $(10.96 \%$ [Bauchi State] $+13.73 \%$ [Gombe State] $) / 2$, indicating that there had been steady increase in TB infection rate in Nigeria over the past 40 years as indicated by previous studies, namely Alhaji [16] reported a $4.4 \%$ prevalence rate in a study of 529 cattle in four states of the Northern region of Nigeria. Eid [17] reported $1.5 \%$ in North Western states,
Ayanwale [18] reported 7.8\% infection rate in a study in some Southern states of Nigeria, while Shehu [26] reported $11.8 \%$ in Kaduna State. Previous studies in both Nigeria and other African countries have shown a similar trend over the years $[24,27,28]$. This may be due to inadequate to none implementation of control policy in the region due to socioeconomic reasons. The herd prevalence obtained in the two states might reflect that bTB infection varies considerably between herds and is widespread in pastoral communities in the study areas. This could be due to the differences in the various communities and other diseases that may be at play with the tubercle bacilli infection.

However, it was observed that fewer animals reacted positively to the tuberculin test among the 2 years old and $<2$ years of age categories and also in the $>4$ years age categories. This finding is similar to the findings by other researchers elsewhere in Africa $[12,14]$. It is possible that the infection may become established in young animals, but as they grow older, there is a delay on set to tuberculin test response. On the other hand, Tizard [29] stated that the other reason for lower response to intradermal tuberculin test in older animals is due to the immune 
decline occurring during the old age or poor nutritional level. Some animals could have been missed resulting in an underestimation of the prevalence. There are several other reasons why tubercle bacilli infected animals give false positive or negative results. Reports by Ameni et al. [14] indicated that infection of cattle with gastrointestinal parasites such as Fasciola and Strongyle compromised the immune response of cattle to the tuberculin test. These infections made the immune response to shift from Th1 to $\mathrm{Th} 2$, thereby promoting the emergence of more false positive results. In endemic areas, delayed hypersensitivity may develop for 3-6 weeks following infection, and in chronically infected animals with severe pathology, the tuberculin test may be unresponsive [30]. This situation is likely to be found in endemic areas such as those in the study areas and may lead to an increase in false negatives with subsequent underestimation of the prevalence. The higher prevalence seen in animals kept under poor management system compared to medium and good management seen in this study is in agreement with reports of other researchers in Africa [12-14]. Poor management system provides an opportunity for the transmission of infection and development of disease and consequently contributing to the variation in the presence of the disease among animals raised under different husbandry systems [12]. Furthermore, poor husbandry system may lead herdsmen to expose their animals to areas where they can be infected as is the case in communal grazing and during borrowing or lending of bulls for breeding as reported by Kaltungo et al. [30].

According to the findings of this study, the infection is more prevalent in cows than in bulls and having poor BCS. Tuberculin reactivity was not significantly affected by body condition of the animal ( $p>0.05)$. However, the slight differences could be due to the fact that tuberculin reactions rely solely on the immune system, which, in turn, may be linked with the management and less likely body condition of the animals such that those manage under good and better management system are immunocompetent and, therefore, give a better reaction to tuberculin as exogenous. However, animals with poor body condition could be a confounder and hence may not determine tuberculin reactivity [31]. This is in contrary to the work of Lackech et al. [32] in which the disease is found to be more prevalent in medium body condition cattle.

From this study, there is a significant association between sex and intradermal skin test positivity $(p<0.05)$. The finding concurs with some previous studies in some African countries, which reported similar findings for bTB positivity between bulls and cows $[33,34]$. Contrary to the findings of this study, other studies have reported no association between sex and intradermal skin positivity $[35,36]$. For example, Inangolet et al. [36] and Cadmus et al. [13] reported female cattle being at higher risk of testing positive than males contrary to findings of Kazwala et al. [35] and Shehu [26] where male cattle were more affected than female cattle, as male cattle mainly castrated are kept longer and hence more chances of contracting the disease than female cattle.

Our findings showed that there was no significant difference in the prevalence of bTB in the two states between the herds sizes (small and large sizes). This observation was due to the fact that majority of the cattle tested were in small size herds. Therefore, to compare and appreciate the significant difference between small and large herd sizes, a comparable number of animals should be tested. This is in contrast to the findings of Cadmus et al. [20] and Cleaveland et al. [34] as there was a statistically significant difference between the herd sizes in Nigeria and Tanzania, respectively.

Breed was not statistically significant in this study ( $>0.05$ ). The tested cattle were mainly of local breeds which were managed under extensive management which might be the reason for the differences in the result, as local breeds are known to be relatively resistant to bTB as compared to Holstein and other western breeds or their crosses that are managed under intensive production system. The result of this study showed that a higher prevalence of bTB was found in Alamari testing area in Bauchi and the lowest was found in Disina. It is assumed that the increased prevalence recorded in Alamari might be due to the presence of Livestock Improvement Breeding Centre which has a great land for pasture and watering points, making pastoralist herds move into the pastures with their cattle in a large number for feeds and water. In Gombe State, the highest prevalence was obtained in Wakaltu, while Poshereng had the lowest. The high prevalence in Wakaltu could be due to the fact that it is an international cattle route as such a lot of herds mixed with each other while passing from one place to another. However, it was recorded that there was no statistically significant difference $(p>0.05)$ in prevalence between the testing area, age, breed, and herd sizes.

\section{Conclusion}

The prevalence recorded in this survey may serve as a baseline data on the status of bTB in cattle in the two states. There is a need for further studies to determine which strains of Mycobacteria species are circulating in those areas between cattle and humans using genetic strain typing methods such as spoligotyping and variable number tandem repeats to characterize them further.

\section{Recommendations}

We recommend for a sustainable project focus on the "Animal Disease Monitoring and Surveillance" in the Northeastern part of the country, where livestock population is so dense with a high burden of bTB. 


\section{Authors' Contributions}

Dr. SI and IAA designed and carried out the research and made the first draft of the article. Drs. BAU, DS, and ASS participated in some field work and contributed in making the final draft, data analyses, and literature searching for the betterment of this article. The overall research was conducted under the supervision of Professor IAA. The author read, finalized, and approved the manuscript.

\section{Acknowledgments}

This survey work was supported by Tertiary Education Trust Fund (TETFUND) research grant number TETF/ES/NRF/013/VOL.1. The support given by the staff of the Veterinary Departments of the two states is highly acknowledged.

\section{Competing Interests} interests

The authors declare that they have no competing

\section{References}

1. Bovine Tuberculosis Disease Information. United States Department of Agriculture; 2016. Available from: https:// www.aphis.usda.gov/aphis/ourfocus/animalhealth. [Last accessed on 2018 Jun 16].

2. Awah-Ndukum J, Kudi CA, Bradley G, Ane-Anyangwe IN., Fon-Tebug S, Tchoumboue J. Prevalence of bovine tuberculosis in abattoirs of the littoral and Western Highland regions of Cameroon: A cause for public health concern. Vet Med Int 2010;2101:Article ID 495015.

3. Ewnetu L, Melaku A, Birhanu A. Bovine tuberculosis prevalence in slaughtered cattle at Akaki municipal abattoir based on meat inspection methods. Glob Vet 2012;9:541-5.

4. Russel DG. Highlighting the parallels between human and animal tuberculosis. J Vet Med Edu 2003;30:140-2.

5. Mamo G, Abebe F, Worku Y, Hussein N, Legesse M, Tilahun $\mathrm{G}$, et al. Bovine tuberculosis and its associated risk factors in pastoral and agro-pastoral cattle herds of Afar region, Northeast Ethiopia. J Vet Med Anim Health 2013;6:171-9.

6. Ashford DA, Whitney E, Raghunatan P, Cosivi O. Epidemiology of selected Mycobacteria that infect humans and other animals. Microbacterial infections in domestic and wild animals. OIE Rev Sci Tech 2001;20:245-52.

7. Berg S, Schelling E, Hailu E, Firdessa R, Gumi B, Erenso, G, et al. Investigation of the high rates of extrapulmonary tuberculosis in Ethiopia reveals no single driving factor and minimal evidence for zoonotic transmission of Mycobacterium bovis infection. BMC Infect Dis 2015;15:112.

8. Radostits DM, Blood DC, Gay CC. Veterinary Medicine: A Textbook of Diseases of Cattle, Sheep, Pig, Goat and Horses. $9^{\text {th }}$ ed. London: Harcourt Publisher Ltd.; 2000. p. 909-18.

9. Müller B, Dürr S, Alonso S, Hattendorf J, Cláudio JM, Sven DC, et al. Zoonotic Mycobacterium bovis-induced tuberculosis in humans. Emerg Infect Dis 2013;19:899-908.

10. Thoen CO, Bloom BR. Pathogenesis of Mycobacterium bovis. In: Thoen CO, Steele JH, editors. Mycobacterium bovis infection in animals and humans. Ames (IA): Iowa State Press; 1995. p. 3-14.

11. Cosivi O, Grange JM, Daborn CJ, Raviglione MC, Fujikura T, Cousins D, et al. Zoonotic tuberculosis due to Mycobacterium bovis in developing countries. Emerg Infect Dis 1998;4:59-70.

12. Asseged B, Lubke-Becker A, Lemma E, Taddele K, Britton S. Bovine TB: A cross-sectional and epidemiological study in and around Addis Ababa. Bull Anim Health Prod Afr 2000;67:71-80.

13. Cadmus SI, Yakubu MK, Magaji AA, Akinbowale OJ, van Soolingen D. Mycobacterium bovis, but also M. africanum present in raw milk of pastoral cattle in North-Central Nigeria. Trop Anim Health Prod 2010;42:1047-8.

14. Ameni G, Vordermeier M, Firdessa R, Aseffa A, Hewinson G, Gordon SV, et al. Mycobacterium tuberculosis infection in grazing cattle in central Ethiopia. Vet $\mathrm{J}$ 2011;188:359-61.

15. Ejeh EF, Markus IF, Ejeh AS, Musa JA, Lawan FA, Ameh JA, et al. Seasonal prevalence of bovine tuberculosis lesion in cattle slaughtered in Yola abattoirs. Bangladesh $\mathrm{J}$ Vet Med 2013;11:113-20.

16. Alhaji I. Bovine Tuberculosis in Four Northern States of Nigeria. PhD Thesis. Ahmadu Bello University, Zaria, Nigeria; 1976a.

17. Eid FS. Some observations on bovine tuberculosis in North States of Nigeria. J Niger Vet Med Assoc 1976;5:35-8.

18. Ayanwale FO. Studies on the Epidemiology of Bovine TB in Some States of Southern Nigeria. Unpublished PhD Thesis, University of Ibadan, Nigeria; 1984. p. 184.

19. Dusai DH, Abdullahi DA. Current status of bovine TB at Sokoto abattoir. Trop Vet 1994;12:134-7.

20. Cadmus SI, Atsanda NN, Oni SO, Akang EE. Bovine tuberculosis in one cattle herd in Ibadan in Nigeria. Vet Med 1984;49:406-12.

21. Bauchi state Diary. http://www.nigeriagalleria.com/ Nigeria/States Nigeria/BauchiState.html. [Last accessed on 2018 Sept 11].

22. NPC, 2006. http://www.nigeriamasterweb.com/Nigeria06 CensusFigs.html., [Last accessed on 2018 Oct 13].

23. Martin, SW,Meek,AH and Willeberg,P (1987).Veterinary Epidemiology Principle and Methods.IOWA State University Press,Ames.

24. Organization Internationale des Epizootics/Organization Internationale des Epizootics (OIE). Manual of Diagnostic Tests and Vaccines for Terrestrial Animals. OIE, Paris France; 2010. Available from: http://www.oie.int. [Last accessed on 14-04-2018].

25. Abubakar IA. Molecular Epidemiology of Human and Bovine Tuberculosis in the Federal Capital Territory and Kaduna State, Ph.D. Thesis, Plymouth University, Plymouth, UK; 2007.

26. Shehu LM. Survey of Tuberculosis and Tubercle Bacilli in Fulani Herds: "Nono" and some Herdsmen in Zaria, Nigeria. M.Sc Thesis, Ahmadu Bello University, Zaria; 1988.

27. Jiwa SF, Kazwala RR, Aboud AA, Kalaye WJ. Bovine tuberculosis in the Lake Victoria Zone of Tanzania and its possible consequences for human health in the HIV/AIDS era. Vet Res Commun 1997;21:533-9.

28. Bugwesa ZK, Mbugi EV, Karimuribo ED, Keyyu JD, Kendall S, Kibiki GS. Prevalence and risk factors for infection of bovine tuberculosis in indigenous cattle in the Serengeti ecosystem, Tanzania. BMC Vet Res 2013;9:267.

29. Tizard I. Veterinary Immunology and Immunopathology. $5^{\text {th }}$ ed. Philadelphia, PA, London: W.B. Saunders; 2000. p. 381-90.

30. Kaltungo BY, Saidu SN, Sackey AK, Kazeem HM. Serological evidence of brucellosis in goats in Kaduna North senatorial district of Kaduna state, Nigeria. ISRN Vet Sci 2013;2013:6

31. De-Lahunta A, Habel RC. Teeth: Applied Veterinary Anatomy. USA: W.B. Saunder Company; 1986. p. 4-12.

32. Lackech E, Achenef M, Ayalew B. Bovine tuberculosis prevalence in slaughtered cattle at Akaki municipal abattoir, based on meat inspection methods. Glob Vet 2012;9:541-5.

33. Gumi B, Schelling E, Firdessa R, Aseffa A, Tschopp R, Yamuah L, et al. Prevalence of bovine tuberculosis in pastoral cattle herds in the Oromia region, Southern Ethiopia. Trop Anim Health Prod 2011;43:1081-7. 
34. Cleaveland S, Shaw DJ, Mfinanga SG, Shirima G, Kazwala RR, Eblate E, et al. Mycobacterium bovis in rural Tanzania: Risk factors for infection in human and cattle populations. Tuberculosis (Edinb) 2007;87:30-43.

35. Kazwala RR, Kambarage DM, Daborn CJ, Nyange J, Jiwa SF, Sharp JM. Risk factors association with the occurrence of bovine tuberculosis in cattle in the
Southern Highland of Tanzania. Vet Res Commun 2001;25:609-14.

36. Inangolet FO, Biffa D, Oloya J, Opuda-Asibo J, Skjerve EA. Cross-sectional study of bovine tuberculosis in the transhumant and agro-pastoral cattle herds in the border areas of Katakwmi and Moroto districts, Uganda. Trop Anim Health Prod 2008;40:501-8.

$* * * * * * * *$ 